\title{
Model Pembelajaran Blended Sebagai Alternatif Pengembangan Mata Kuliah Praktikum (Studi Kasus Praktikum Routing dan Switching) \\ Irmawati $^{1}$ \\ Teknik Elektro Politeknik Negeri Ujung Pandang \\ Email: irmawati@poliupg.ac.id ${ }^{1}$
}

\begin{abstract}
ABSTRAK
Mata kuliah praktikum yang dilaksanakan pada umumnya menggunakan model pembelajaran sinkron dengan tatap muka langsung pada laboratorium dengan sumber belajar yang disediakan.Pada praktikum Routing dan Switching, memanfaatkan sumber belajar yang tersedia pada sistem e-learning, namun ini tidak memiliki alur pembelajaran yang dapat menuntun mahasiswa untuk mempelajari semua konten yang tersedia. Penelitian ini bertujuan untuk menghasilkan rancangan pembelajaran blendedpada Praktikum Routing dan Switching dengan memanfaatkan modul lesson pada sistem e-learning. Metode yang digunakan menggunakan model prosedural dimulai dari mereview capaian pembelajaran mata kuliah, merancang pembelajaran blended dan alur pembelajaran pada sistem e-learning. Penelitian ini menghasilkan rancangan model pembelajaran blended dengan kombinasi pembelajaran asinkron dengan sinkron tatap muka $75 \%$ dan menghasilkan alur pembelajaran memanfaatkan modul lesson pada sistem e-learning.
\end{abstract}

Kata Kunci:Model Blendel, Praktikum, Asinkron, Sinkron Tatap Muka, e-learning

\begin{abstract}
The practicum courses carried out in general use a synchronous learning model with face-toface the laboratory with the learning resources provided. On practicum Routing and Switching, making use of the learning resources available on e-learning systems, but this lacks a learning path that can guide students for all available content. This research is intended to produce. In e-learning learning. The method used using the procedural model starts from reviewing the achievement of subject learning, learning assemblies. This study resulted in blended learning model with combination of asynchronous learning with 75\% syncronization and resulted learning module learning flow in e-learning system.
\end{abstract}

Keywords:Blendel Model, Practicum, Asynchronous, Sync Face-Down, e-learning

\section{Pendahuluan}

Kata pembelajaran, sekarang ini, lebih banyak digunakan untuk mengganti kata pengajaran.Padahal, pembelajaran memiliki makna yang berbeda dibandingkan dengan pengajaran.Pembelajaran merujuk ke memfasilitasi belajar, sedangkan pengajaran merujuk ke arah mengajar (interaksi dengan pengajar sebagai sumber belajar utama).

Pembelajaran adalah upaya menata lingkungan sebagai sumber belajar agar terjadi proses belajar pada diri si pembelajar. Upaya menata lingkungan dilakukan dengan menyediakan sumber-sumber belajar,misalnya: guru, buku teks, bahan pembelajaran, narasumber, televisi, VCD, radio-kaset, majalah, koran, internet, CDROM, lingkungan dan bahkan juga temannya sendiri. Ukuran keberhasilan pembelajaran adalah proses terjadinya interaksi. Bukan terletak pada pengajar yang menyampaikan informasi (mengajar).Dengan demikian, rekayasa pembelajaran yang utama adalah penyediaan sumber-sumber belajar.Pengajar bukan satu- 
satunya sumber belajar, ia hanya salah satu bagian dari sumber belajar.

Teknologi dan informasi komunikasi yang berkembang sangat pesat membawa dampak terhadap kebutuhan konsep dan mekanisme belajar mengajar berbasis teknologi informasi. Konsep e-learning membawa pengaruh terhadapproses transformasi pendidikan konvensional ke dalam bentuk digital, baik secara konten maupun sistemnya. Esensi pembelajaran daring adalah menciptakan pengalaman belajar seoptimal mungkin dengan memanfaatkan teknologi daring secara tepat dan seoptimal mungkin (Chaeruman, 2017).

Blended learning merupakan bentuk baru dari pembelajaran berbasis e-learning, merupakan istilah yang sekarang ini banyak digunakan padamodel pembelajaran dimana implementasi pembelajaran dilakukan melalui kombinasi antara pembelajaran konvensional dan pembelajaran dengan menggunakan bantuan teknologi informasi dan komunikasi (Thorne, 2003).

Blended learning dipandang sebagai pendekatan pedagogis yang menerapkan berbagai pendekatan pembelajaran ketimbang dilihat dari seberapa besar delivery system antara face-to-face dibandingkan dengan secara online. Melalui blended learning semua sumber belajar yang dapat memfasilitasi terjadinya belajar bagi orang yang belajar dikembangkan.

Blended learning mengkombinasikan secara arif, relevan dan tepat antara potensi face-to facedengan potensi teknologi informasi dan komunikasi yang demikian pesat berkembang saat inisehingga memungkinkan:

1. Terjadinya pergeseran paradigma pembelajaran dari yang dulunya lebih berpusat pada pengajar menuju paradigma baru yang berpusat pada pembelajar (student-centered elarning).

2. Terjadinya peningkatan interaksi atau interaktifitas antara pembelajar dengan pengajar, sesama pembelajar, serta interaksi dengan konten dan sumberbelajar lainnya.

Program Studi Teknik Komputer dan Jaringan (TKJ) telah menerapkan pembelajaran melalui teknologi internet. Fasilitas e-learning pada situs https://elearning.poliupg.ac.id

diimplementasikan untuk memfasilitasi kuliah tatap muka dengan memposting materi kuliah, pemberian tugas dan ujian melalui elearning. Penggunaan e-learning ini masih pada tahap awal baru pada tataran sebagai suplemen dari pembelajaran/kuliah tatap muka, dimanaproporsi online pada beberapa mata kuliah Prodi TKJ ini masih terbilang kurang, sekitar kurang lebih $30 \%$.

Mata kuliah praktikum yang dilaksanakan pada umumnya menggunakan model pembelajaran sinkron dengan tatap muka langsung pada laboratorium dengan sumber belajar yang disediakan. Mata kuliah praktikum ini mengadopsi kurikulum Cisco Academy dengan memanfaatkan sumber belajar aplikasi simulasi Packet Tracer dan menggunakan perangkat router dan switch di laboratorium program studi. Sumber belajar disediakan pada sistem e-learning, namun ini tidak memiliki alur pembelajaran yang dapat menuntun mahasiswa untuk mempelajari semua konten yang tersedia

Penelitian ini bertujuan untuk menghasilkan rancangan pembelajaran blended pada Praktikum Routing dan Switching dengan memanfaatkan modul lesson pada sistem e-learning.

\section{Metode Penelitian}

Langkah-langkah penelitian meliputi pengumpulan informasi, melakukan perencanaan dengan menganalisis capaian pembelajaran mata kuliah, pengembangan bentuk awal produk berupa rancangan pembelajaran hingga alur pembelajaran. Langkah-langkah ini ditunjukkan pada gambar 1.Pengumpulan informasi berupa informasi capaian dan peta kompetensipembelajaran mata kuliah Praktikum Routing dan Switching. 
Melakukan perencanaan dengan menganalisis kebutuhan pada mata kuliah ini sampai pada pokok bahasan serta pokok materi. Pengembangan bentuk awal produk berupa perancangan seting pembelajaran sinkron dan asinkron berdasarkan pokok materi, perancangan media dan asesmen yang dibutuhkan.

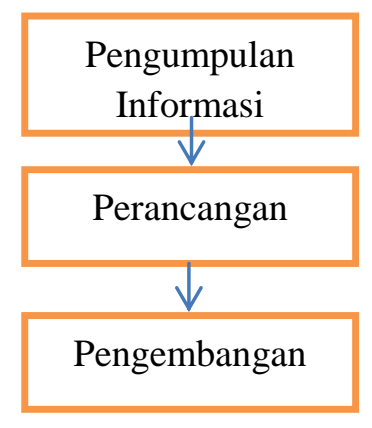

Gambar 1. Langkah-langkah penelitian

Capaian pembelajaran mata kuliah ini mencakup 3 ranah kemampuan intelektual, yaitu kognitif, afektif dan psikomotorik.Kompetensi yang ingin dicapai dirancang hingga level C4 (analyzing) untuk ranah kognitif, P3 (precision)untuk ranah psikomotorik, dan A3 (valuing) untuk ranah afektif.Untuk pencapaian ranah psikomotorik, didesain dua model pembelajaran yaitu model pembelajaran sinkron tatap muka dengan didahului model pembelajaran asinkron mandiri dan kolaboratif.Model pembelajaran asinkron mandiri disediakan sumber belajar dari berbagai media, mahasiswa dapat menambah pengetahuan dengan mengakses sumber belajar yang disediakan.Model pembelajaran kolaboratif didesain untuk memberikan ruang diskusi pada mahasiswa untuk mengajukan pertanyaan maupun pernyataan terkait pokok bahasan.Implementasi model pembelajaran asinkron ini pada sistem e-learning memanfaatkan modul lesson pada LMS
moodle.Dirancang sebagai serangkaian kegiatan mahasiswa dengan memasukkan sebagai unsur penilaian.

Model pembelajaran sinkron tatap muka dapat dilakukan apabila mahasiswa telah melakukan serangkaian kegiatan pada pembelajaran asinkron mandiri dan kolaboratif.

\section{Hasil Penelitian}

Penelitian ini menghasilkan capaian pembelajaran yang berisi peta kompetensi mata kuliah, rancangan pembelajaran blended dengan mengkombinasikan pembelajaran asinkron dan sinkron tatap muka serta alur pembelajaran.

Mata kuliah praktikum menuntut adanya pertemuan antara pengajar dan mahasiswa sehingga desain pembelajaran dirancang dengan porsi pembelajaran sinkron tatap muka dengan kombinasi dengan pembelajaran sinkron. Model blended yang dirancang mengkombinasikan antara pembelajaran sinkron tatap muka dengan asinkron dengan menyediakan sumber belajar.Sumber belajar ini mendukung untuk semua pencapaian baik kognitif, afektif maupun psikomotorik.

Setting belajar dan aktivitas pembelajaran yang dirancang seperti pada tabel 1 .

Tabel 1. Setting belajar dan aktivitas pembelaran

\begin{tabular}{|l|l|}
\hline $\begin{array}{l}\text { Sinkron Tatap } \\
\text { Muka Langsung }\end{array}$ & $\begin{array}{l}\text { Asinkron Mandiri } \\
\text { dan Kolaboratif }\end{array}$ \\
\hline - Ceramah & -Membaca \\
- Diskusi & -Menonton video \\
- Praktek Simulasi & -Simulasi \\
- Praktek Lab & -Mengerjakan tugas \\
& -Partisipasi dalam \\
& forum online \\
\hline
\end{tabular}


Pada gambar 2 terlihat alur pembelajaran yang dirancang secarameliputi apa saja yang dilakukan oleh pengajar ataupun sistem e-learning, dan apa saja yang dilakukan oleh mahasiswa.Dosen pengampuh menyediakan sumber belajar pada sistem e-learning. Sumber belajar berupa modul yang akan diakses oleh mahasiswa dan dipelajari sebelum tatap muka dengan tutor mata kuliah ini. Sehingga pada saat tatap muka, mahasiswa memiliki pengetahuan dasar tentang materi atau langkah-langkah apa saja yang akan dilakukan pada sesi tatap muka di laboratorium. Setelah tatap muka, pembelajaran diakhiri dengan setting evaluasi pembelajaran yang disimpan pada sistem e-learning.

Pada sistem e-learning ini memanfaatkan beberapa modul/aktivitas.Modul lesson, quiz, forum dan beberapa resource untuk menampilkan sumber belajar yang dibutuhkan untuk mencapai tujuan pembelajaran pada setiap pokok bahasan.

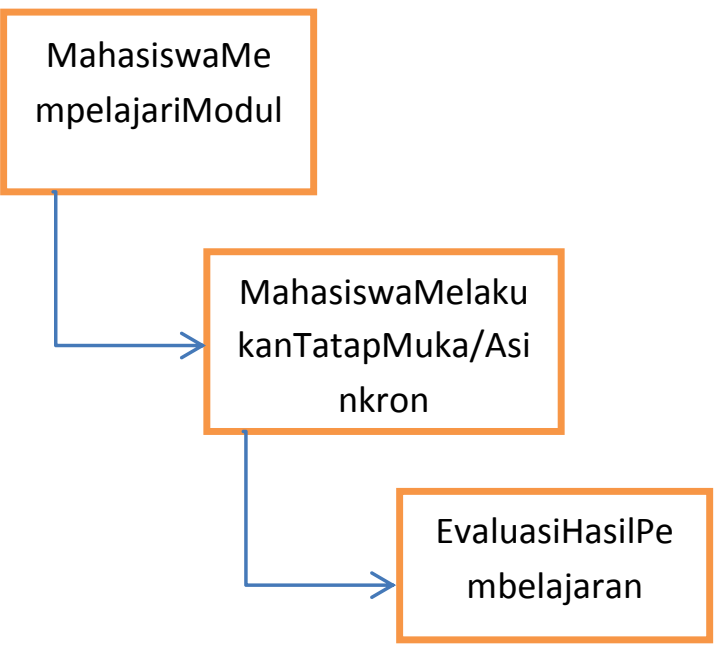

Gambar 2. Alur Pembelajaran Blended
Implementasi pada sistem e-learning moodle memanfaat beberapa modul dan sumber daya (gambar 3).Pada halaman awal mata kuliah, ditampilkan beberapa gambaran visual kepada mahasiswa untuk memberikan pengenalan awal tentang mata kuliah ini.

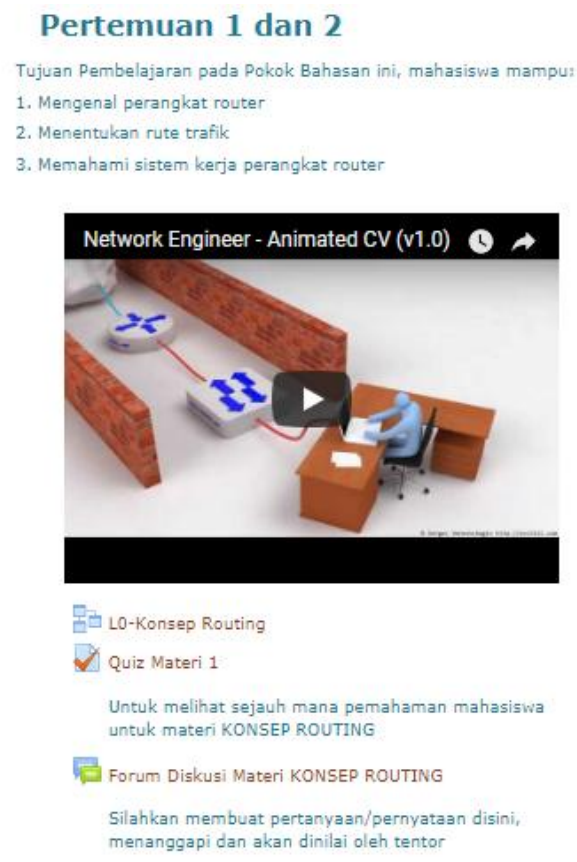

Gambar 3. Implementasi dan sistem elearning

Modul lesson merupakan salah satu modul yang memiliki banyak fitur yang sesuai dengan hasil rancangan alur pembelajaran mata kuliah ini.Pada gambar 4 menunjukkan aktivitas pada modul lesson.Lesson ditujukan agar dosen mampu membuat aktivitas yang menarik dan fleksibel.Lesson terbagi menjadi beberapa halaman dan diakhir setiap halaman bisa ditambahkan pertanyaan yang memiliki beberapa jawaban. Jawaban yang dipilih mahasiswaakan menentukan halaman mana yang akan diaksesnya. 


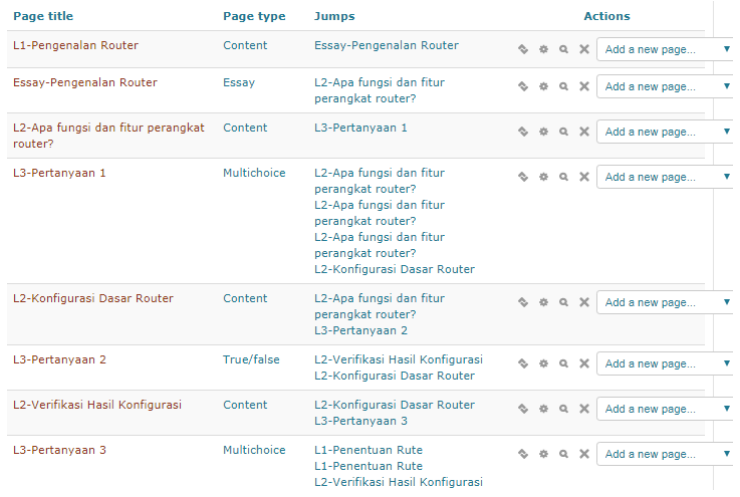

Gambar 4. Penggunaan modul lesson

Aktivitas yang dilakukan pada sistem elearning ini dapat dipantau secara realtime melalui fasilitas report seperti pada gambar 5.

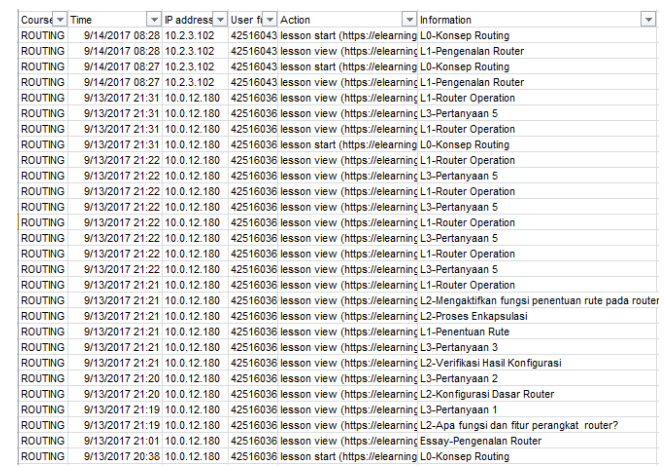

Gambar 5. Aktivitas pada modul lesson sistem e-learning

Sistem e-learning menyediakan sistem penilaian yang terhubung dengan semua aktivitas pembelajaran.Setiap aktivitas pada modul lesson dapat menjadi unsur nilai pada sistem e-learning.Sistem penilaian ini dapat disetting sesuai dengan daftar pemberian nilai akhir mahasiswa.Pada gambar 6, unsur penilaian ujian tengah semester, ujian akhir semester dan nilai praktikum menjadi unsur pemberian nilai akhir.Nilai praktikum terdiri dari beberapa unsur sesuai dengan hasil perancangan pmbelajaran.Terdiri atas aktifitas pada lesson, nilai observasi terhadap mahasiswa dan nilai quiz.

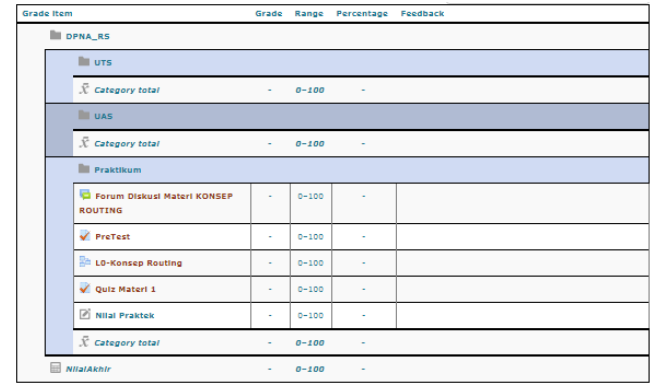

Gambar 6. Format penilaian sistem elearning

\section{Kesimpulan}

Penelitian ini memberikan alternative pembelajaran bagi mata kuliah praktikum dengan memanfaatkan model blended. Dengan memanfaatkan fitur pada sistem elearning dapat membantu penerapan hasil perancangan dan alur pembelajaran.

\section{Daftar Pustaka}

[1] Thorne, Kaye. 2003.Blended Learning: How to Integrate Online and Traditional Learning. $A C M$ Digital Library.

[2] Chaeruman, Uwes Anis. 2017. PEDATI, Model Desain Sistem Pembelajaran Blended. Direktorat Pembelajaran Kementrian Riset, Teknologi dan Pendidikan Tinggi. 